\title{
Investigation on Dynamic Propagation Characteristics of In-Plane Cracks in PVB Laminated Glass Plates
}

\author{
Xiaoqing Xu, Bohan Liu, and Yibing Li \\ State Key Laboratory of Automotive Safety \& Energy, Department of Automotive Engineering, Tsinghua University, \\ Beijing 100084, China \\ Correspondence should be addressed to Yibing Li; liyb@mail.tsinghua.edu.cn
}

Received 12 March 2016; Revised 19 May 2016; Accepted 9 June 2016

Academic Editor: Majid R. Ayatollahi

Copyright (C) 2016 Xiaoqing Xu et al. This is an open access article distributed under the Creative Commons Attribution License, which permits unrestricted use, distribution, and reproduction in any medium, provided the original work is properly cited.

\begin{abstract}
Polyvinyl butyral (PVB) laminated glass has been widely used as an important component of mechanical and construction materials. Cracks on PVB laminated glass are rich in impact information, which contribute to its impact resistance design. In this paper, a three-dimensional (3D) numerical simulation model describing PVB laminated glass under impact loading is firstly established and validated qualitatively and quantitatively compared with the corresponding experimental results recorded by the high-speed photography system. In the meantime, the extended finite element method (XFEM) is introduced to analyze the crack propagation mechanism of laminated glass based on dynamic stress intensity factors (DSIFs) and propagations of stress waves. Parametric studies are then carried out to investigate the influence of five critical parameters, that is, plate dimension, crack length, impact energy, glass properties, and PVB properties, on crack propagation characteristics of laminated glass. Results show that the interaction between crack tip and stress waves as well as the propagations of stress waves corresponds to the fluctuations of DSIFs at crack tip. Both the structure and material variables are proven to play a very important role in glass cracking DSIFs and thus govern the crack propagation behavior. Results may provide fundamental explanation to the basic crack propagation mechanism on radial cracks in PVB laminated glass under impact loading conditions, thus to instruct its impact design improvement.
\end{abstract}

\section{Introduction}

Due to its excellent transparency, formability, and impact resistance, polyvinyl butyral (PVB) laminated glass becomes great potential transparent protective material and has been widely used in both automotive and construction industry. The impact of foreign objects on laminated glass can generate microcracks, which will gradually extend and eventually lead to the failure of laminated glass. Regardless of whether fracture failure occurs, the fragility of glass layer and the good adhesion of PVB interlayer ensure the integrity of sandwiched structure and make the structure have certain energy absorption characteristics and toughness, which effectively improve the security of laminated structure. In order to utilize laminated glass as transparent protective material more effectively, its cracking propagation behavior under impact conditions needs to be comprehensively studied. However, dynamic failure characteristics of laminated glass are very complex; therefore studies on its dynamic cracking propagation characteristics become increasingly necessary.
In recent years, investigations on mechanical properties of PVB laminated glass have been thoroughly conducted, ranging from quasi-static mechanical properties [1-4] to dynamic impact response [4-10]. In general, the impact test in accordance with its impact velocity can be divided into three categories, that is, low-speed drop-weight test [11-13], high-speed impact test with air gun [3, 14, 15], and explosion shock wave impact test $[6,9,10,16]$, where low-speed drop-weight test is one of the most widely used testing methods to evaluate the material critical failure conditions and its fracture mechanism. Lee et al. [17] and Park and Chen [14], respectively, studied the static and dynamic crack propagation behavior in layered glass cross adhesive interlayers. Failure wave was introduced to account for their observations. Zhang et al. [18] and $\mathrm{Hu}$ et al. [19] experimentally and numerically studied failure conditions and crack morphologies in brittle plate with a thin polymer backing under various impact velocities and concluded the determining factors to predict its dynamic fracture patterns, that is, elastic properties, fracture energy, and accurate stress 
wave tracing model. Meanwhile, Vandenberghe et al. [20] investigated crack patterns in brittle plate upon controlled transverse impact using a global scaling law to predict the number of radial cracks. Also, the coexistence of radial and circumferential cracks was observed. As for a further step, $\mathrm{Xu}$ et al. [21] and Chen et al. [22] conducted out-ofplane dynamic loading test on PVB laminated glass based on drop-weight combined with high-speed photography system. Velocity and acceleration time history for both radial and circular cracks were calculated to understand the crack initiation and propagation mechanism. It is found that radial cracks appear earlier than circular ones with higher propagation speed. Furthermore, Chen et al. [23, 24] investigated in-plane crack propagation behavior in PVB laminated glass plate via captured in-plane and interplane cracking process and found that the supported glass layer would always initiate before the loaded layer with the same final radial crack morphologies. The quantity effect of radial cracks on its propagation behavior was also thoroughly investigated.

Numerical simulation attracts more and more attentions to investigate the fracture mechanism of PVB laminated glass for its simplicity and efficiency [5, 8, 25-32]. Bennison et al. [33] studied the stress distribution and fracture sequence in PVB laminated glass upon biaxial flexure loading using finite element method (FEM) and found the relationship between crack initiation and maximum stress location. Meanwhile, $\mathrm{Xu}$ and $\mathrm{Li}$ [34] numerically investigated the crack evolutions on PVB laminated windshield plate subjected to pedestrian head. It was found that the plastic deformation, radial cracks, and circular cracks were mainly caused by shear stress, compressive stress, and tensile stress, respectively. Furthermore, a series of newly developed numerical simulation methods are increasingly applied to researches on fracture characteristics of PVB laminated glass for their unique advantages in cracking simulation. Xu and Zang [35], Zang et al. [36], and Gao and Zang [37] investigated the impact fracture mechanism of PVB laminated glass on the basis of discrete element method (DEM). Chen et al. [38] numerically investigated the cracking behavior of PVB laminated glass beam under lowvelocity impact in the framework of cohesive zone modeling with the glass-ply cracking modeled by extrinsic cohesive model. The propagations of stress waves during cracking process were also primarily analyzed. Based on extended finite element method (XFEM), Xu et al. [39] and Xu et al. [40] established PVB laminated glass plate model subjected to impact loading validated by both radial crack velocity and crack morphology and deeply investigated its radial and circular crack propagation mechanism.

However, as a key parameter to indicate the cracking driving force and interpret the crack propagation behavior in cracking mechanism analysis, dynamic stress intensity factor (DSIF) cannot be easily obtained via experimental methods. The propagations of stress waves during cracking can also have significant effect on cracking response of PVB laminated glass under impact loading. Besides, seldom numerical studies are available in exploring the cracking behavior of PVB laminated glass during out-plane impact loading from the perspective of DSIFs and stress waves. It is therefore necessary to investigate the dynamic crack propagation behavior of

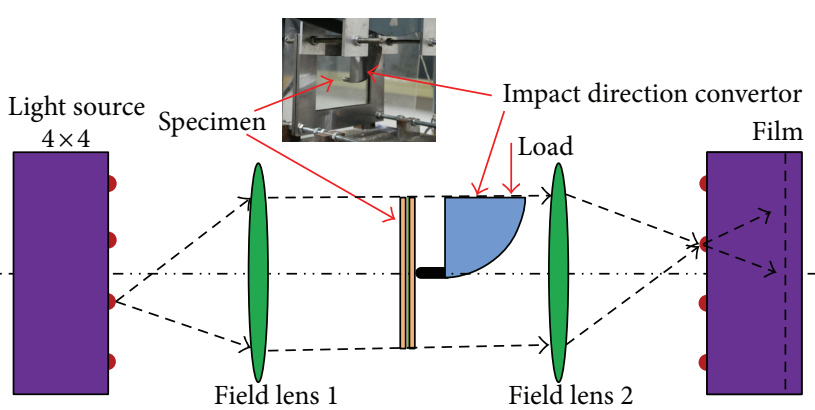

FIGURE 1: The schematic diagram of experimental system combing drop-weight test device with high-speed photography system.

PVB laminated glass on the basis of DSIFs and stress waves. Hence, the numerical model of PVB laminated glass plate with a layered structure is established in this study. The numerical model in simulations with propagation is then validated via the comparison between simulation and experimental results of radial crack propagation process, which are recorded by the high-speed photography system. Further, the time history of DSIFs is calculated in simulations with fixed crack, and the interaction between stress waves and crack tip is also introduced to interpret the relationship between crack propagation behavior and its driving force. Finally, parametric studies on five critical parameters, that is, plate dimension, crack length, impact energy, glass properties, and PVB properties, are conducted based on XFEM, which reveals the laws of crack propagation behavior on PVB laminated glass plates.

\section{Experimental and Numerical Details}

2.1. Experiment Setup. The drop-weight device combined with high-speed photography experimental system [21-23] is sketched in Figure 1 . The $150 \mathrm{~mm} \times 200 \mathrm{~mm}$ rectangular specimen of laminated glass is used in the experiment, which consists of a $0.76 \mathrm{~mm}$ PVB interlayer sandwiched by two $2 \mathrm{~mm}$ soda-lime glass sheets and is fabricated with the same processing technology of industrial automotive windshield. The drop-weight device is used to apply vertical load via free fall with different height. Meanwhile, the impact direction convertor with hemispherical end transfers the vertical load to horizontal load at the specimen center, that is, a load direction perpendicular to specimen plane. The high-speed photography system is adopted to record the real time crack propagation process on glass layer of specimen. The radial crack morphology is recorded on the film and crack propagation speed is calculated [22].

2.2. Computational Model. In this study, the three-dimensional (3D) finite element (FE) model consisting of an impactor, a prefabricated crack, and a PVB laminated glass plate is shown in Figure 2. One-quarter of the laminated plate and impactor are modeled to take advantage of the structure symmetry. The cylinder impactor has a mass of 


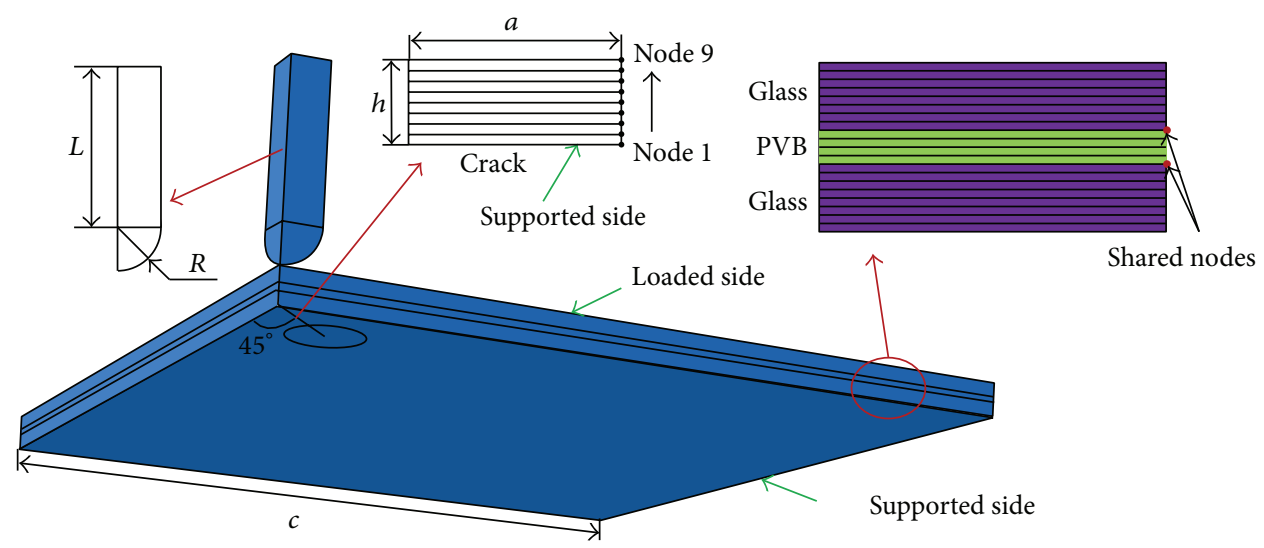

FIGURE 2: The overview of PVB laminated glass computational model subjected to impact loading.

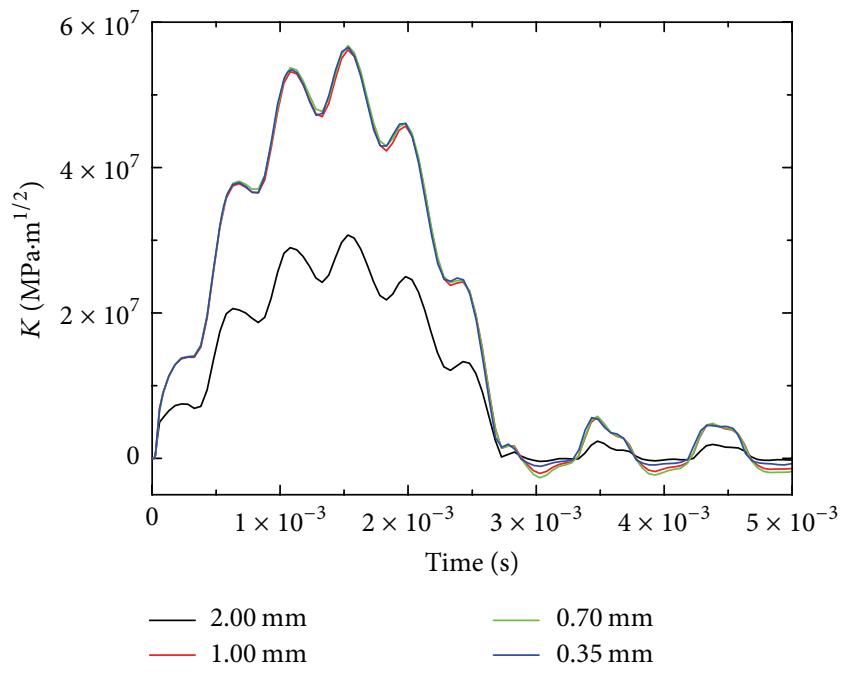

FIGURE 3: The mode I DSIFs of different mesh sizes at node 1 with fixed crack length of $0.02 \mathrm{~m}$ and impact speed of $5 \mathrm{~m} / \mathrm{s}$.

$2 \mathrm{~kg}$ via equivalent density with the same mass of experimental impactor. The $2 \mathrm{~mm}$ thick crack with the length of $a$ (shown in Figure 2) is placed at the center of laminated plate in the glass layer of supported side and the angle between crack and structure symmetry line is 45 degrees. In order to eliminate the influence of structural asymmetry, square laminated plate model with dimensions of $200 \mathrm{~mm} \times$ $200 \mathrm{~mm}$ on plane direction is introduced to study its crack propagation characteristics. The laminated plate model is meshed with $2 \mathrm{~mm} \times 2 \mathrm{~mm}$ (in plane direction) 3D eightnode reduced integration solid (C3D8R) elements. Since stress concentration exists and the stress gradients are very large at crack tip, the crack tip area needs to be meshed with sufficient fine elements to achieve stress and strain accurately. For this purposes, four mesh sizes at crack tip area in plane direction, that is, $0.35 \mathrm{~mm} \times 0.35 \mathrm{~mm}, 0.7 \mathrm{~mm} \times 0.7 \mathrm{~mm}$, $1 \mathrm{~mm} \times 1 \mathrm{~mm}$, and $2 \mathrm{~mm} \times 2 \mathrm{~mm}$, are applied to achieve a stable convergence of the computational model. The results are shown in Figure 3, where the mode I DSIFs of node 1 (node 1 to node 9 at crack tip are defined in Figure 2) with fixed crack length $a=0.02 \mathrm{~m}$ under the impact speed of $5 \mathrm{~m} / \mathrm{s}$ are illustrated. As can be seen, all simulations show the same oscillation frequencies and the mesh refinement has only effect on oscillation amplitudes. Therefore, the configuration of $0.35 \mathrm{~mm} \times 0.35 \mathrm{~mm}$ can be used for further simulations sufficiently. In longitudinal direction, the laminated structure of specimen is modeled with 20 element layers, wherein the outside 8 element layers represent glass layers and the inner 4 element layers stand for the PVB interlayer (shown in Figure 2). Therefore, each layer of the laminated structure has more than three integration points to guarantee the accuracy of calculation and analysis in longitudinal direction.

Clamped boundary conditions of the laminated plate model and frictionless surface-to-surface contact between impactor and specimen are adopted to simulate the real experimental conditions. As typical viscoelastic material, PVB interlayer is simulated with a linear elastic model with a shear modulus $G=G_{0}$ and bulk modulus $K$, combined with a viscoelastic model. The elastic modulus $E_{\mathrm{PVB}}$ and Poisson's ratio $v$ are described as [42]

$$
\begin{aligned}
E_{\mathrm{PVB}} & =\frac{9 K G_{0}}{3 K+G_{0}}, \\
\nu & =\frac{3 K-2 G_{0}}{6 K+2 G_{0}},
\end{aligned}
$$

where $K$ and $G_{0}$ are bulk modulus and short time shear modulus of PVB, respectively. The generalized Maxwell model using Prony series with one term is introduced to simulate the viscoelasticity of PVB [42]:

$$
G(t)=G_{\infty}+\left(G_{0}-G_{\infty}\right) e^{-\beta t},
$$

where $G(t)$ is the relaxation modulus which is the function of time $t, G_{\infty}$ is long time shear modulus, and $\beta$ is decay factor.

As typical brittle material, glass layers are defined by linear elastic model. Reference parameters of glass layer, PVB interlayer, and impactor are listed in Table 1.

The computational model with the same dimensions of experimental system is set up using a cylinder impactor and a laminated plate model [39] to verify the effectiveness of the 
TABLE 1: Basic parameters for numerical model.

\begin{tabular}{|c|c|c|}
\hline & Properties & Reference parameters \\
\hline \multirow{6}{*}{ Glass layer $[40,41]$} & Density & $2500 \mathrm{~kg} / \mathrm{m}^{3}$ \\
\hline & Young's modulus & $70 \mathrm{GPa}$ \\
\hline & Poisson’s ratio & 0.22 \\
\hline & Maximum allowable principal stress & $60 \mathrm{MPa}$ \\
\hline & Energy release rate: $G_{\mathrm{IC}}, G_{\mathrm{IIC}}, G_{\mathrm{IIIC}}$ & $G_{\mathrm{IC}}=10 \mathrm{~J} / \mathrm{m}^{2}, G_{\mathrm{IIC}}=G_{\mathrm{IIIC}}=50 \mathrm{~J} / \mathrm{m}^{2}$ \\
\hline & Thickness $t_{\text {glass }}$ & $2 \mathrm{~mm}$ \\
\hline \multirow{5}{*}{ PVB interlayer $[41,42]$} & Density & $1100 \mathrm{~kg} / \mathrm{m}^{3}$ \\
\hline & Shear modulus: $G_{0}, G_{\infty}$ & $G_{0}=0.33 \mathrm{GPa}, G_{\infty}=0.69 \times 10^{-3} \mathrm{GPa}$ \\
\hline & Decay factor $\beta$ & $12.6 \mathrm{~s}^{-1}$ \\
\hline & Bulk modulus $K$ & $20 \mathrm{GPa}$ \\
\hline & Thickness $t_{\mathrm{PVB}}$ & $0.76 \mathrm{~mm}$ \\
\hline \multirow{5}{*}{ Impactor } & Mass & $2 \mathrm{~kg}$ \\
\hline & Young's modulus & $207 \mathrm{GPa}$ \\
\hline & Poisson’s ratio & 0.22 \\
\hline & Length $L$ & $20 \mathrm{~mm}$ \\
\hline & Radius $R$ & $5 \mathrm{~mm}$ \\
\hline
\end{tabular}

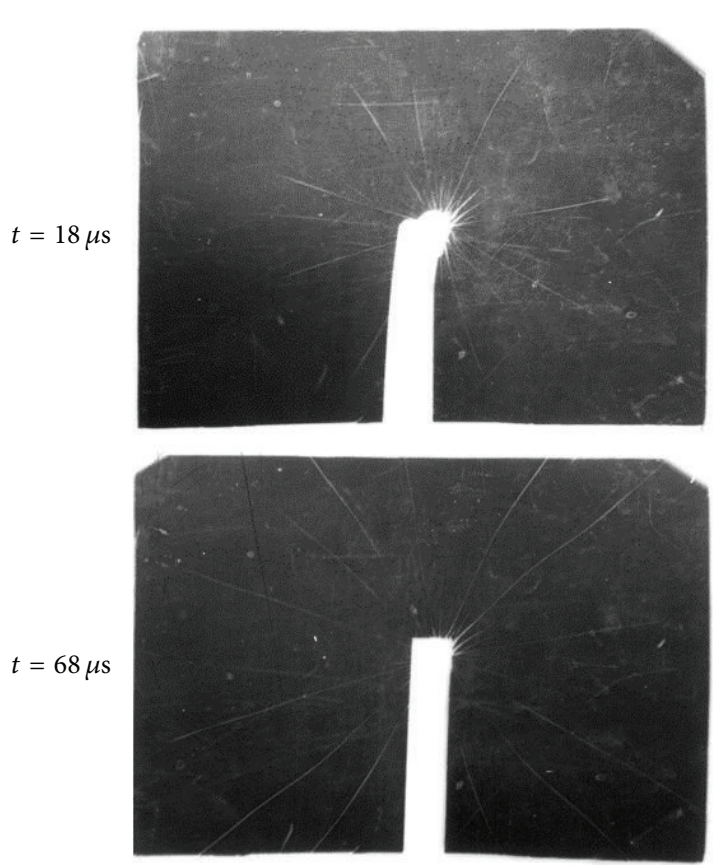

(a) Experiment results
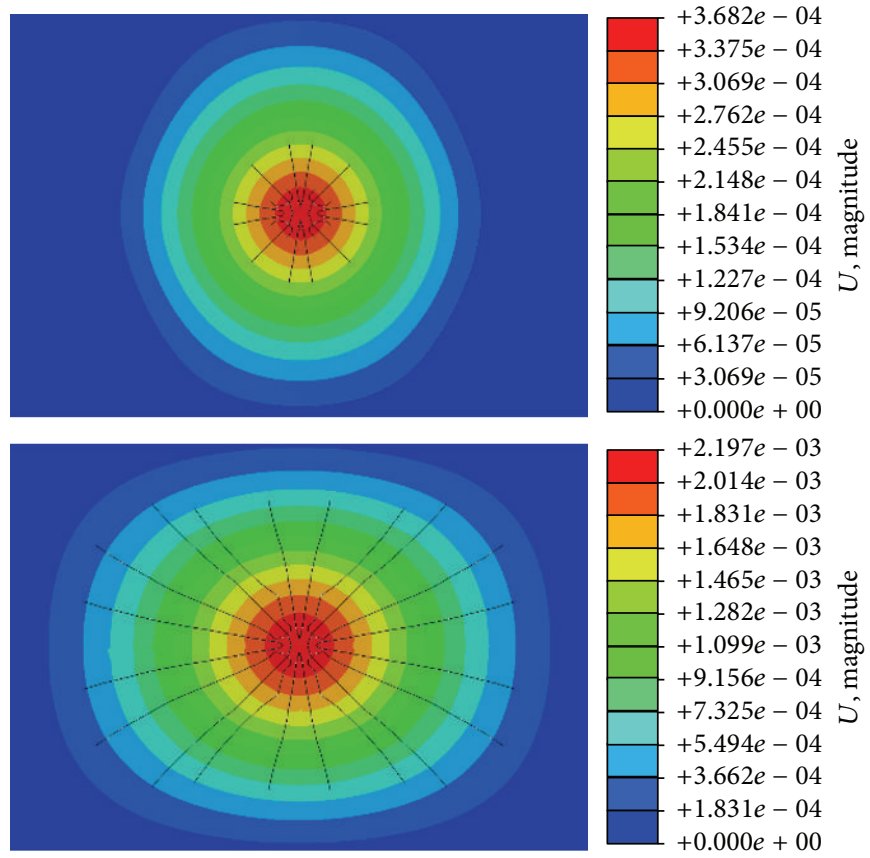

(b) Simulation results (unit: $\mathrm{m}$ )

FIGURE 4: Qualitative verification: comparison of radial crack morphologies between simulation results and experimental results.

abovementioned model. The experimental system model is then verified in simulations with propagation via qualitative method (radial crack morphology) and quantitative method (crack propagation velocity) shown in Figures 4 and 5, respectively. As can be seen from Figure 4, a total of 22 radial cracks exist in experimental images and most of them have propagated to the border of the specimen shown in Figure 4(a). In comparison, 20 radial cracks in all have propagated close to the border in simulation images shown in Figure 4(b). Thus, both the crack propagation process and the morphology of cracks in simulation agree well with the experimental results. Figure 5 shows the comparison of crack velocity time history curves between experiment and simulation results. As can be observed, the cracks propagation time history in simulation is recorded from the increment of the original crack, for initial flaws are preembedded in the model. Another difference between the experimental and simulation results is that the gradient of the descending stage of the velocity curves in simulation is smaller than that in experiment. The responsible reason should be the 
rubber pad used between the mental clamp and glass sheet to avoid possible damage during screwing in experiment. The rebound velocity in simulation is higher in simulation where no cushion pad is provided. So the peak value as well as the time history of the simulation results is in good agreement with the experimental results. The computational results are in good agreement with the corresponding experimental results from both qualitative perspective and quantitative perspective. Therefore, a reliable FE model with fairly high quality is established and can be adopted for further studies on crack behavior of PVB laminated glass.

2.3. Fundamentals of XFEM. The extended finite element method XFEM, which is a numerical technique based on generalized finite element method and the partition of unity method, extends the piecewise polynomial function space of conventional finite element methods with extra enrichment functions. XFEM does not need to be updated to track the crack path and can obtain accurate solution with coarse mesh $[43,44]$.

The displacement interpolation of XFEM is described as below [43]:

$$
\begin{aligned}
\mathbf{u}^{h} & (\mathbf{x}) \\
& =\sum_{I \in N_{\mathrm{I}}} N_{I}(\mathbf{x})\left[\mathbf{u}_{I}+H(\mathbf{x}) \mathbf{a}_{I}+\sum_{\alpha=1}^{4} \sum_{J \in N_{\Lambda}} F_{\alpha}(\mathbf{x}) \mathbf{b}_{J}^{\alpha}\right],
\end{aligned}
$$

where $N_{\Gamma}$ is the number of nodes in elements cut by crack; $N_{\Lambda}$ is the number of nodes in elements with crack tip; $N_{I}(\mathbf{x})$ are the conventional shape functions; $\mathbf{u}_{I}$ are the nodal DOFs for conventional shape functions; $\mathbf{a}_{I}$ and $\mathbf{b}_{I}^{\alpha}$ are the nodal DOFs associated with the Heaviside function $H(\mathbf{x})$, with the value above the crack and -1 below the crack. The crack tip enrichment functions $F_{\alpha}(\mathbf{x})$ are expressed as [43]

$$
\begin{aligned}
& {\left[F_{\alpha}(\mathbf{x}), \alpha=1 \sim 4\right]=\left[\sqrt{r} \sin \frac{\theta}{2}, \sqrt{r} \cos \frac{\theta}{2}, \sqrt{r} \sin \theta\right.} \\
& \left.\cdot \sin \frac{\theta}{2}, \sqrt{r} \sin \theta \cos \frac{\theta}{2}\right],
\end{aligned}
$$

where $\mathbf{x}$ is an integration point and $(r, \theta)$ denote the coordinate values from a polar coordinate system located at the crack tip.

Details of XFEM can be found in [43-45].

2.4. Calculation of Dynamic Stress Intensity Factors. In linear fracture mechanics, for example, soda-lime glass, the dynamic stress intensity factors $\left(K_{\mathrm{I}}^{\text {Dyn }}, K_{\mathrm{II}}^{\text {Dyn }}, K_{\mathrm{III}}^{\text {Dyn }}\right)$ are widely used to characterize the stress and displacement fields near the crack tip, where $K_{\mathrm{I}}^{\text {Dyn }}, K_{\mathrm{II}}^{\text {Dyn }}$, and $K_{\mathrm{III}}^{\text {Dyn }}$ are mode I, II, and III DSIFs. DSIFs relevant to energy release rate $(J$ integral) can be described as

$$
J=\frac{1}{8 \pi} \bar{K}^{T} \cdot \bar{B}^{-1} \cdot \bar{K}
$$

where $\bar{K}=\left[K_{\mathrm{I}}^{\text {Dyn }}, K_{\mathrm{II}}^{\text {Dyn }}, K_{\mathrm{III}}^{\text {Dyn }}\right]^{T}$ is SIF vector and $\bar{B}$ is the prelogarithmic energy factor matrix, which is diagonal for

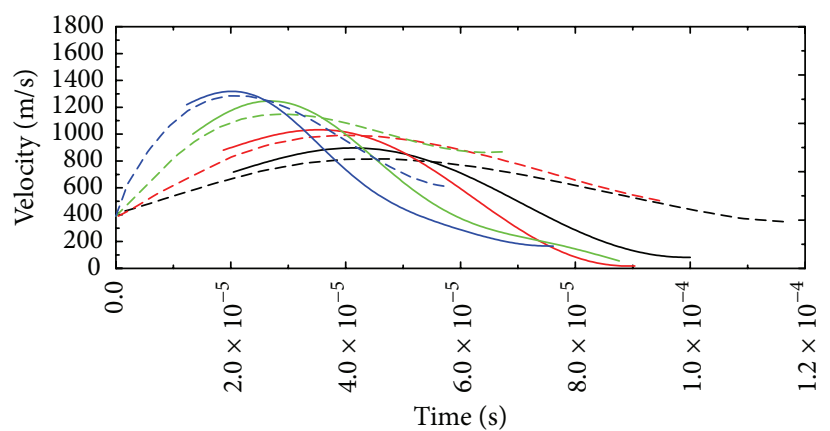

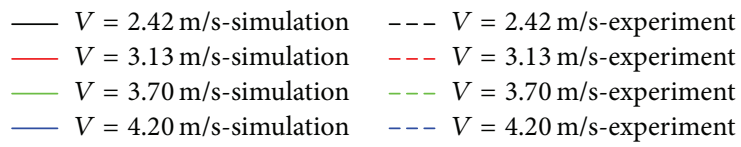

FIGURE 5: Quantitative verification: comparison of crack propagation velocities between simulation results and experimental results.

homogeneous and isotropic materials. Therefore the equation can be simplified to

$$
J=\frac{1}{E^{*}}\left[\left(K_{\mathrm{I}}^{\text {Dyn }}\right)^{2}+\left(K_{\mathrm{II}}^{\text {Dyn }}\right)^{2}\right]+\frac{1}{2 G}\left(K_{\mathrm{III}}^{\text {Dyn }}\right)^{2},
$$

where $E^{*}=E$ for plane stress and $E^{*}=E /\left(1-\nu^{2}\right)$ for plane strain.

The interaction integral method [46] is introduced to calculate DSIFs for cracks under mixed-mode loading, instead of according to a known $J$-integral. The $J$-integral can be described as

$$
\begin{aligned}
J= & \frac{1}{8 \pi}\left[K_{\mathrm{I}}^{\text {Dyn }} B_{11}^{-1} K_{\mathrm{I}}^{\text {Dyn }}+2 K_{\mathrm{I}}^{\text {Dyn }} B_{12}^{-1} K_{\mathrm{II}}^{\text {Dyn }}\right. \\
& \left.+2 K_{\mathrm{I}}^{\text {Dyn }} B_{13}^{-1} K_{\mathrm{III}}^{\text {Dyn }}+\left(\text { terms not involving } K_{\mathrm{I}}^{\text {Dyn }}\right)\right] .
\end{aligned}
$$

With regard to an auxiliary pure mode I crack tip field, the DSIF $k_{\mathrm{I}}^{\text {Dyn }}$ can be defined as

$$
J_{\text {aux }}^{\mathrm{I}}=\frac{1}{8 \pi} k_{\mathrm{I}}^{\text {Dyn }} B_{11}^{-1} k_{\mathrm{I}}^{\text {Dyn }} .
$$

Then overlay the auxiliary field on the actual field yields

$$
\begin{aligned}
J_{\text {tot }}^{\mathrm{I}} & =\frac{1}{8 \pi}\left[\left(K_{\mathrm{I}}^{\text {Dyn }}+k_{\mathrm{I}}^{\text {Dyn }}\right) B_{11}^{-1}\left(K_{\mathrm{I}}^{\text {Dyn }}+k_{\mathrm{I}}^{\text {Dyn }}\right)\right. \\
& +2\left(K_{\mathrm{I}}^{\text {Dyn }}+k_{\mathrm{I}}^{\text {Dyn }}\right) B_{12}^{-1} K_{\mathrm{II}}^{\text {Dyn }} \\
& +2\left(K_{\mathrm{I}}^{\text {Dyn }}+k_{\mathrm{I}}^{\text {Dyn }}\right) B_{13}^{-1} K_{\mathrm{III}}^{\text {Dyn }} \\
& \left.+\left(\text { terms not involving } K_{\mathrm{I}}^{\text {Dyn }} \text { or } k_{\mathrm{I}}^{\text {Dyn }}\right)\right] .
\end{aligned}
$$

Since

$$
\begin{aligned}
& \left.\left(\text { terms not involving } K_{\mathrm{I}}^{\text {Dyn }}\right)\right|_{J} \\
& \quad=\left.\left(\text { terms not involving } K_{\mathrm{I}}^{\text {Dyn }} \text { or } k_{\mathrm{I}}^{\text {Dyn }}\right)\right|_{J_{\mathrm{tot}}^{\mathrm{I}}}
\end{aligned}
$$


the interaction integral for mode I field can be expressed as

$$
\begin{aligned}
J_{\text {int }}^{\mathrm{I}} & =J_{\text {tot }}^{\mathrm{I}}-J-J_{\text {aux }}^{\mathrm{I}} \\
& =\frac{k_{\mathrm{I}}^{\mathrm{Dyn}}}{4 \pi}\left(B_{11}^{-1} K_{\mathrm{I}}^{\mathrm{Dyn}}+B_{12}^{-1} K_{\mathrm{II}}^{\mathrm{Dyn}}+B_{13}^{-1} K_{\mathrm{III}}^{\mathrm{Dyn}}\right) .
\end{aligned}
$$

For mode II and mode III, similar results can be obtained:

$$
\begin{aligned}
& J_{\text {int }}^{\mathrm{II}}=\frac{k_{\mathrm{II}}^{\mathrm{Dyn}}}{4 \pi}\left(B_{21}^{-1} K_{\mathrm{I}}^{\mathrm{Dyn}}+B_{22}^{-1} K_{\mathrm{II}}^{\mathrm{Dyn}}+B_{23}^{-1} K_{\mathrm{III}}^{\mathrm{Dyn}}\right) \\
& J_{\text {int }}^{\mathrm{III}}=\frac{k_{\mathrm{III}}^{\mathrm{Dyn}}}{4 \pi}\left(B_{31}^{-1} K_{\mathrm{I}}^{\mathrm{Dyn}}+B_{32}^{-1} K_{\mathrm{II}}^{\mathrm{Dyn}}+B_{33}^{-1} K_{\mathrm{III}}^{\mathrm{Dyn}}\right) .
\end{aligned}
$$

2.5. Crack Propagation Criteria. In static case, the open mode crack propagation criteria are generally expressed as $K_{\mathrm{I}} \geq$ $K_{\text {IC }}$, where $K_{\mathrm{I}}$ and $K_{\mathrm{IC}}$ (for glass: $K_{\mathrm{IC}} \approx 0.7 \mathrm{MP} \sqrt{\mathrm{m}}$ ) are static stress intensity factor and static fracture toughness, respectively. Similarly, the dynamic open mode crack propagation criteria are defined as $K_{\mathrm{I}}^{\text {Dyn }}(t) \geq K_{\mathrm{IC}}^{\text {Dyn }}$ [47], where $K_{\mathrm{I}}^{\text {Dyn }}(t)$ related to time $t$ is DSIF and $K_{\mathrm{IC}}^{\mathrm{Dyn}}$ associated with strain rate is dynamic fracture toughness. $K_{\mathrm{I}}^{\text {Dyn }}(t)$ is determined by experiments, while $K_{\mathrm{IC}}^{\mathrm{Dyn}}$ is determined through dynamic structural analysis. Since the cracks are generated in linear elastic glass layer, the influence of loading rate on $K_{\mathrm{IC}}^{\text {Dyn }}$ can be neglected within the scope of our discussion impact velocity $[48,49]$. Therefore, the rate sensitivity of $K_{\mathrm{IC}}^{\text {Dyn }}$ for glass layer can be ignored in the analysis of laminated glass fracture mechanism, that is, $K_{\mathrm{IC}}^{\mathrm{Dyn}} \approx K_{\mathrm{IC}} \approx 0.7 \mathrm{MP} \sqrt{\mathrm{m}}$.

2.6. Cracking Propagation Direction. The maximum tangential stress criterion is adopted to compute the cracking propagation direction, where $K_{\mathrm{III}}^{\mathrm{Dyn}}$ is not taken into consideration in these criteria. In the case of $\partial \sigma_{\theta \theta} / \partial \theta=0$ (or $\tau_{r \theta}=0$, where $\sigma$ and $\tau$ are normal stress and tangential stress, resp., and $r$ and $\theta$ are polar coordinates at the crack tip in a plane perpendicular to the crack plane), the crack propagation angle relative to the crack plane can be obtained [46]:

$\widehat{\theta}$

$$
=\cos ^{-1}\left(\frac{3\left(K_{\mathrm{II}}^{\text {Dyn }}\right)^{2}+\sqrt{\left(K_{\mathrm{I}}^{\text {Dyn }}\right)^{4}+8\left(K_{\mathrm{I}}^{\text {Dyn }}\right)^{2}\left(K_{\mathrm{II}}^{\text {Dyn }}\right)^{2}}}{\left(K_{\mathrm{I}}^{\text {Dyn }}\right)^{2}+9\left(K_{\mathrm{II}}^{\text {Dyn }}\right)^{2}}\right),
$$

where $\widehat{\theta}=0$ indicates the crack propagation in a straight direction. $\hat{\theta}>0$ corresponds to $K_{\mathrm{II}}^{\mathrm{Dyn}}<0$, while $\widehat{\theta}<0$ stands for $K_{\mathrm{II}}^{\mathrm{Dyn}}>0$.

2.7. Simulations with Fixed Crack. According to our previous experimental studies [23], there are three types of cracks in PVB laminated plate under impact loading, that is, radial cracks in supported side, radial cracks in loaded side, and circumferential cracks in supported side, where supported side and loaded side are defined in Figure 2. Besides, radial cracks appear before circumferential cracks, while radial cracks in supported side are generated earlier than radial cracks in loaded side and radial cracks in both sides overlap completely. Therefore, the study on radial cracking propagation behavior in supported side is fairly important for investigating the fracture properties of PVB laminated glass.

Then, a series of numerical simulations on dynamic response of laminated glass with a fixed crack are conducted under different impact conditions using commercial finite element software ABAQUS. In our simulations, the crack is specified to be stationary and the material in crack tip should be in pristine condition to predict the crack propagation. Five structure and material variables, that is, plate dimension, crack length, impact energy, glass properties, and PVB properties, are introduced to conduct parametric studies in Section 4, and the detailed variable settings in parametric study are listed in Table 2 with other parameters kept at their reference values shown in Table 1.

\section{Analysis of the Time History of DSIFs}

In the condition of dynamic fracture, DSIFs are functions of time and the in-depth analysis of the time history of DSIFs helps to fully understand the crack propagation characteristics. Figure 6(a) shows the velocity and acceleration time history of impactor with the initial velocity of $5 \mathrm{~m} / \mathrm{s}$, and the corresponding mode I, II, and III DSIFs of node 1 at crack tip are shown in Figure 6(b). It can be seen that both the acceleration curve and DSIF curves exhibit regular fluctuations in the same law before $3 \times 10^{-3} \mathrm{~s}$, while the acceleration curve almost has no fluctuation and DSIF curves still have slight regular fluctuations after $3 \times 10^{-3} \mathrm{~s}$. Since the impactor has been away from the plate after $3 \times 10^{-3} \mathrm{~s}$, the existence of stress waves leads to the fluctuations of DSIF curves in the entire time course and the crest appears when crack tip interacts with stress waves, indicating that the interaction between crack tip and stress waves accounts for the DSIFs' changes. Therefore, the time of interaction between the crack tip and stress waves corresponds to the fluctuation crests of DSIFs.

Since $\left|K_{\mathrm{I}}^{\mathrm{Dyn}}\right|$ is much larger than $\left|K_{\mathrm{II}}^{\mathrm{Dyn}}\right|$ and $\left|K_{\mathrm{III}}^{\mathrm{Dyn}}\right|$ (Figure 6), the crack tip field is mixed-mode crack tip filed which mode $I$ is in dominance $[21,22]$, that is, the mixedmode DSIF $K^{\text {Dyn }} \approx K_{\mathrm{I}}^{\text {Dyn }}$, and mode I DSIF can be introduced to represent mixed-mode DSIF. Figure 7 shows the mode I DSIF time history of node 1 to node 8 at crack tip under the impact velocity of $5 \mathrm{~m} / \mathrm{s}$ (Figure 7 (b) shows the data before $5 \times 10^{-5} \mathrm{~s}$ ). As can be seen, mode I DSIFs of node 1 to node 8 at crack tip begin to rise rapidly after a time lag which is defined as lag time, then fluctuate in the same regularity under the impact stress waves, and finally fluctuate slightly with the crest decreasing under the residual stress waves, so the entire process can be divided into three stages: lag stage, interaction stage, and residual stage. The propagation process of stress waves is introduced to explain this phenomenon (shown in Figure 8): the impact generates the compressive stress waves, which propagate from the loaded side to the supported side in the thickness direction. 
TABLE 2: The detailed variable settings in parametric numerical study.

\begin{tabular}{|c|c|c|}
\hline \multicolumn{2}{|c|}{ Numerical variables } & Reference parameters \\
\hline Plate dimension $(\mathrm{m} \times \mathrm{m})$ & & $0.05 \times 0.05,0.1 \times 0.1,0.2 \times 0.2$ \\
\hline Crack length $(\mathrm{m})$ & & $0.01,0.02,0.04$ \\
\hline \multirow{2}{*}{ Impact energy } & Impact velocity (m/s) & $2,5,8,10,15,20$ \\
\hline & Impact mass (kg) & $0.32,2,8$ \\
\hline \multirow{2}{*}{ Glass properties } & Young's modulus (GPa) & $7,70,700$ \\
\hline & Density $\left(\mathrm{kg} / \mathrm{m}^{3}\right)$ & $250,2500,25000$ \\
\hline \multirow{4}{*}{ PVB properties } & Young's modulus & $0.1 E_{\mathrm{PVB}}, E_{\mathrm{PVB}}, 10 E_{\mathrm{PVB}}$ \\
\hline & Density $\left(\mathrm{kg} / \mathrm{m}^{3}\right)$ & $110,1100,11000$ \\
\hline & Shear modulus ratio & $2.1 \times 10^{-4}, 2.1 \times 10^{-3}, 2.1 \times 10^{-2}$ \\
\hline & Delay factor $\left(\mathrm{s}^{-1}\right)$ & $0.126,12.6,1260$ \\
\hline
\end{tabular}

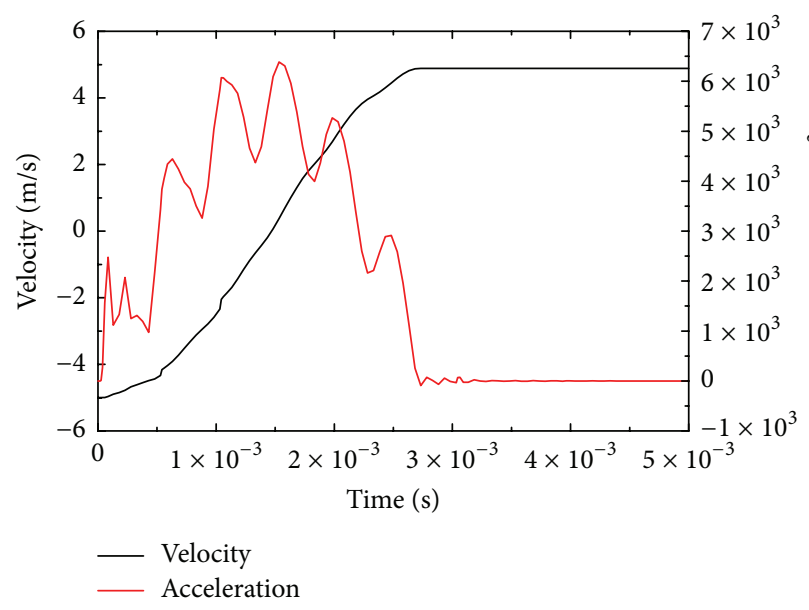

(a) Velocity and acceleration time history of impactor

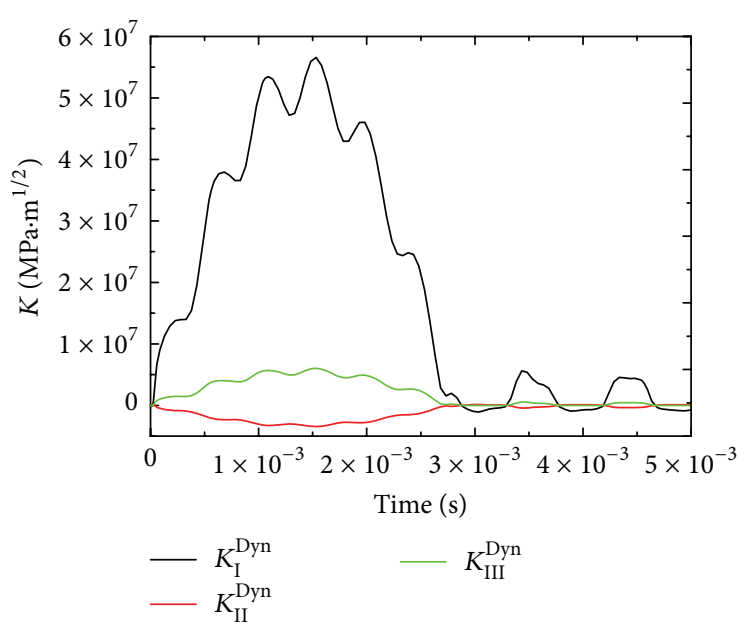

(b) Mode I, II, and III DSIFs of node 1 at crack tip

FIGURE 6: Simulation results with the impact velocity of $5 \mathrm{~m} / \mathrm{s}$ and crack length of $0.02 \mathrm{~m}$.

Then the compressive stress waves reflect from the supported side (free surface) into tension stress waves, which consist of shear wave, longitudinal wave, and Rayleigh wave. The tension stress waves further propagate to the boundaries and reflect to the crack tip (shear wave and longitudinal wave through glass layer, while Rayleigh wave through free surface of supported side), which results in the crests of DSIFs. Besides, mode I DSIFs of node 1 to node 8 decrease one by one for the weakening of reflected tension stress waves during propagation, while there is almost no difference in peak times of these nodes for the extremely high propagation velocity of stress waves. Therefore, the round-trip propagation of tension stress waves leads to the fluctuations of DSIFs.

The velocities of involved stress waves are expressed as follows [50]:

$$
\begin{aligned}
c_{l} & =\sqrt{\frac{E(1-\nu)}{(1-2 v)(1+\nu) \rho}} \\
c_{s} & =\sqrt{\frac{E}{2(1+\nu) \rho}} \\
c_{R} & \approx 0.495 c_{l},
\end{aligned}
$$

where $c_{l}, c_{s}$, and $c_{R}$ stand for the velocities of longitudinal wave, shear wave, and Rayleigh wave, respectively, besides $c_{l}=\max \left\{c_{l}, c_{s}, c_{R}\right\} ; E, v$, and $\rho$ represent Young's modulus, Poisson's ratio, and density, respectively. The layer interfaces can cause large amounts of stress wave reflection and further dramatically delay the stress wave propagation. Similar delays have also been discovered in other experimental researches [14]. Therefore, the lag time of DSIF, which is the shortest propagation time of compressive stress waves from loaded side to supported side, can be expressed as

$$
\begin{aligned}
t_{l} & \approx 2 \cdot t_{\mathrm{Glass}}+t_{\mathrm{PVB}}+2 \cdot t_{\text {Interface }} \\
& =\left.2 \cdot \frac{d}{c_{l}}\right|_{\text {Glass }}+\left.\frac{d}{c_{l}}\right|_{\mathrm{PVB}}+2 \cdot t_{\text {Interface }},
\end{aligned}
$$

where $t_{\mathrm{Glass}}, t_{\mathrm{PVB}}$, and $t_{\text {Interface }}$ represent propagation time of longitudinal wave through glass layers, PVB interlayer, and layer interfaces, respectively. Analogously, the interval of propagation time between node 1 and node 8 should be

$$
\left.t_{\text {Interval }} \approx \frac{d}{c_{l}}\right|_{\text {Glass }} \approx 3.54 \times 10^{-7} \mathrm{~s}
$$




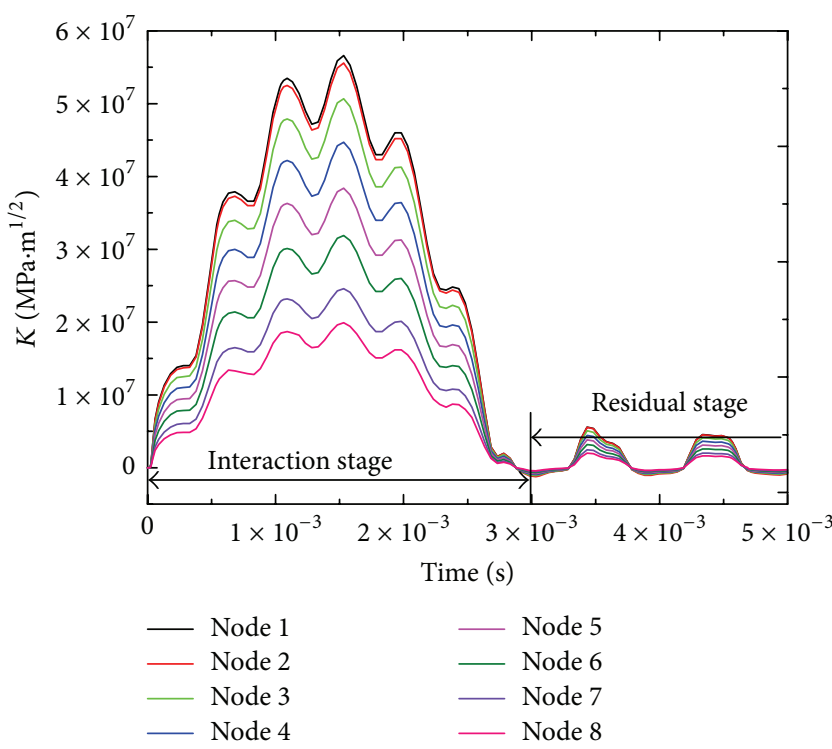

(a) Mode I DSIF curves of entire time course

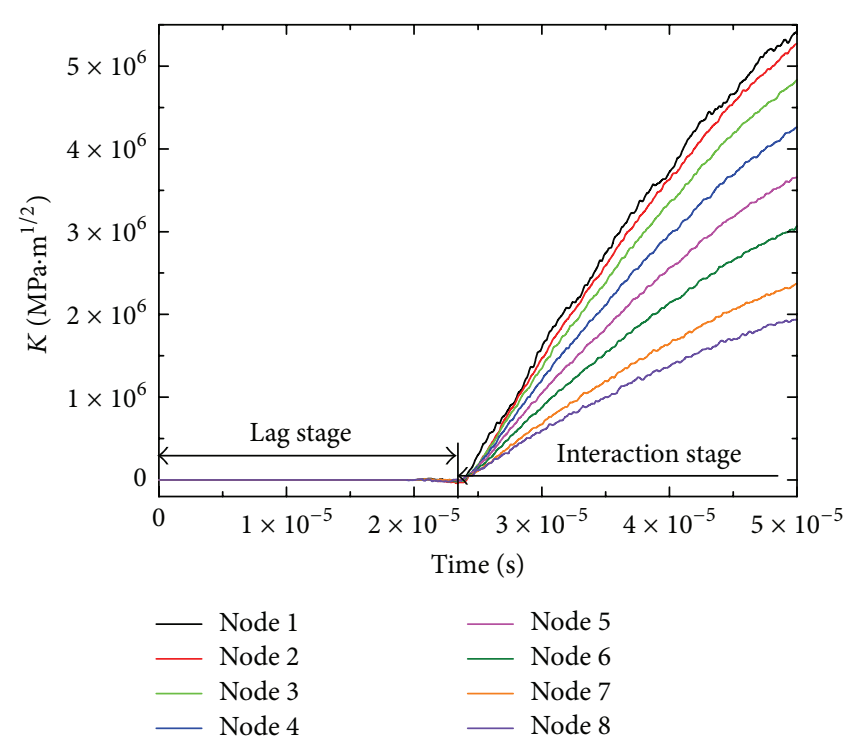

(b) Mode I DSIF curves before $5 \times 10^{-5} \mathrm{~s}$

FIGURE 7: The mode I DSIF time history of node 1 to node 8 at crack tip with the impact velocity of $5 \mathrm{~m} / \mathrm{s}$ and crack length of $0.02 \mathrm{~m}$.

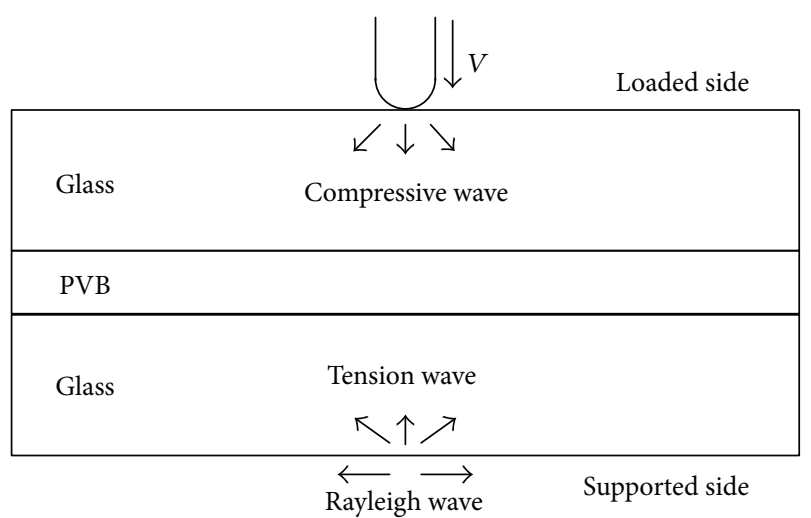

FIGURE 8: The propagation process of stress waves.

Furthermore, the time when DSIF increases to dynamic fracture toughness with the stress waves accumulation, that is, $K^{\text {Dyn }} \approx K_{\mathrm{IC}}^{\text {Dyn }} \approx K_{\mathrm{IC}} \approx 0.7 \mathrm{MP} \sqrt{\mathrm{m}}$, is considered as the simulated propagation time. The simulated crack propagation times of node 1 to node 8 and the corresponding linear fitting results are illustrated in Figure 9; then the simulated propagation time interval between node 1 and node 8 can be calculated as $4.55 \times 10^{-7} \mathrm{~s}$ which is in good agreement with theoretical calculation.

According to the stress wave propagation theory, crack propagation firstly occurs at node 1 , so parametric studies on crack propagation characteristics focus on mode I DSIF at node 1 in Section 4.

\section{Discussions}

4.1. Effects of Plate Dimension. Three different plate dimensions $(0.05 \mathrm{~m} \times 0.05 \mathrm{~m}, 0.1 \mathrm{~m} \times 0.1 \mathrm{~m}$, and $0.2 \mathrm{~m} \times 0.2 \mathrm{~m})$

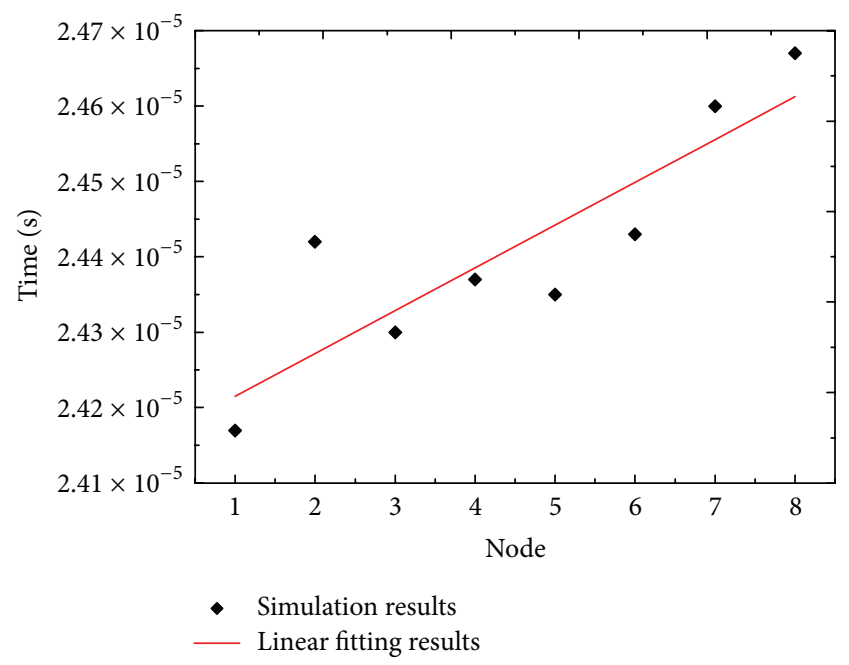

FIGURE 9: The simulated crack propagation times of node 1 to node 8 and the corresponding linear fitting curve.

in plane direction are considered to study the dimension effect on cracking propagation characteristics of glass layer. Figure 10 gives the effect of plate dimension on mode I DSIF of node 1. As can be seen, the interaction stage is getting longer and the peak DSIF would be smaller with the increase of plate size under the same impact energy due to the decrease of structure stiffness. The time that the stress wave propagation needed from the crack tip to the plate borders and return to the crack tip becomes longer due to the increase of plate edge length; therefore the time interval of DSIF peaks, that is, fluctuation cycle, increases with the increase of plate size which is fully consistent with the simulation results as shown in Figure 10. 


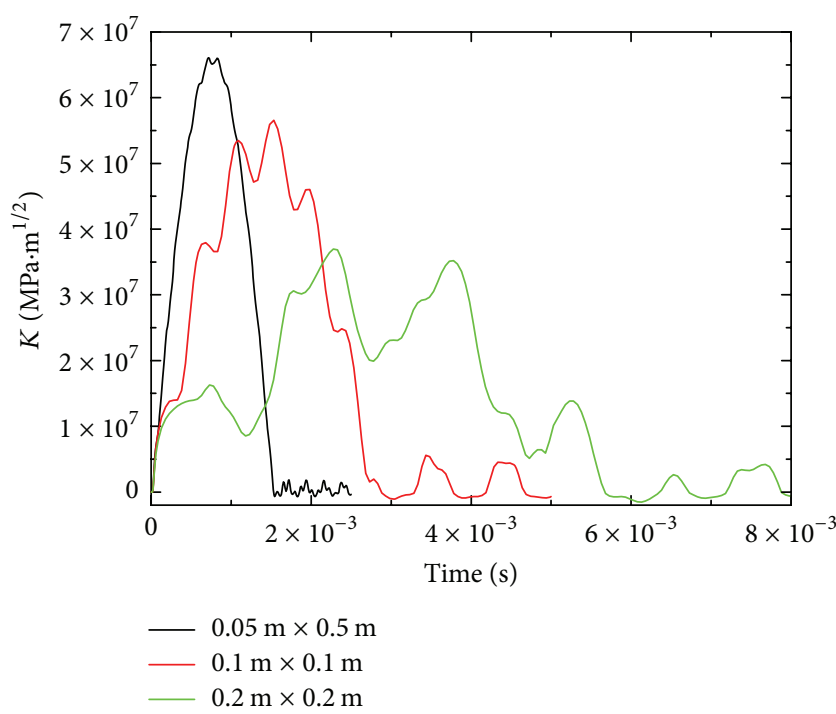

FIgURE 10: Mode I DSIF curves at node 1 of different plate dimensions with the impact velocity of $5 \mathrm{~m} / \mathrm{s}$ and crack length of $0.02 \mathrm{~m}$.

4.2. Effects of Crack Length. Figure 11 shows the mode I DSIF curves at node 1 with different fixed crack lengths $(0.01 \mathrm{~m}$, $0.02 \mathrm{~m}$, and $0.04 \mathrm{~m}$ ) under the impact velocity of $5 \mathrm{~m} / \mathrm{s}$. As can be seen, with the increase of fixed crack length, the lag time increases proportionally (Figure 11(b)) and the peak times are postponed with fluctuation frequency (reciprocal of fluctuation cycle) changing slightly (Figure 11(a)). Since the pre-crack length increases, the stress wave propagation path from impact point to crack tip increases, which leads to the increase of lag time, and the propagation path from crack tip to proximal border decreases, while it increases to distal border, which results in the changes of fluctuation frequency. In addition, the DSIF decreases with the increase of pre-crack length, due to the increase of propagation path from impact point to crack tip which leads to the increased stress wave weakening.

4.3. Effects of Impact Energy. Two aspects, that is, impact velocity and impact mass, are introduced to investigate the influence of impact energy on cracking propagation characteristics of glass layer. The mode I DSIFs of node 1 with different impact velocities and impact masses are given in Figures 12(a) and 12(b), respectively. As shown in Figure 12, both the increase of impact velocity and impact mass lead to the increase of peak mode I DSIF at all stages and almost have no effect on fluctuation frequency of DSIF curve. Besides, the interaction time between impactor and plate increases with the increase of impact mass but is not affected by impact velocity. Since the acceleration of impactor is mainly affected by impact velocity, the rebound time of impactor increases with the impact mass and almost has no change with impact speed. In summary, the increase of impact energy results in the increase of stress wave accumulation, that is, peak DSIF, while it has little influence on stress wave propagation velocity, that is, fluctuation frequency.
4.4. Effects of Glass Properties. In static case, stress intensity factors have nothing to do with material's Young's modulus and density. However, under impact loading conditions, the stress wave accumulation at crack tip leads to the crack propagation; thus stress wave propagation speed plays a critical role in crack propagation characteristics. As can be seen from (14), longitudinal wave, shear wave, and Rayleigh wave velocities are all functions of Young's modulus and density. Besides, stress wave velocities are proportional to Young's modulus and inversely proportional to density.

Figures 13(a) and 13(b) show the effects of glass Young's modulus $E_{\text {Glass }}$ and density $\rho_{\text {Glass }}$ on mode I DSIF at node 1. As can be observed, larger Young's modulus corresponds to the shorter interaction stage and larger peak DSIF owing to the increase of structure stiffness, while density changes have little effect on the length of interaction stage and peak DSIF with structure stiffness unchanged. Besides, the lag time increases and the peak times are postponed, for the decrease of Young's modulus or the increase of density leads to the decrease of stress wave velocities. Furthermore, the stress wave propagation time becomes longer with the decrease of Young's modulus or the increase of density; therefore the fluctuation frequency increases with the increase of Young's modulus or the decrease of density, which agrees well with the simulation results shown in Figure 13.

4.5. Effects of PVB Properties. As longitudinal boundaries of cracks in glass layers, PVB interlayer has an important influence on DSIFs of glass layer. Figures 14(a) and 14(b) show the effects of PVB Young's modulus $E_{\mathrm{PVB}}$ and density $\rho_{\mathrm{PVB}}$ on mode I DSIF curves at node 1 . As can be seen, the interaction stage and peak DSIF decrease with the increase of PVB Young's modulus due to the increase of structure stiffness, while density changes have little effect on the length of interaction stage and peak DSIF with structure stiffness unchanged. Moreover, the fluctuation frequency increases with the increase PVB Young's modulus or the decrease of PVB density. According to (14), the stress wave propagation velocities in glass layer are far higher than that in PVB interlayer; thus the existence of PVB interlayer has an inhibiting effect on the stress wave propagation in glass layer, which leads to the increase of stress wave propagation time in glass layer.

The viscosity $\eta$ in the one-term generalized Maxwell model can be expressed as

$$
\eta=\left(G_{0}-G_{\infty}\right) \tau=\frac{\left(G_{0}-G_{\infty}\right)}{\beta} .
$$

As seen, shear modulus ratio $G_{\infty} / G_{0}$ and delay factor $\beta$ are two main viscosity factors, which are inversely proportional to viscosity. Figures 14(c) and 14(d) give the effects of shear modulus ratio and delay factor on mode I DSIF curves at node 1. One may draw conclusion that the interaction stage, peak DSIF, and fluctuation cycle decrease with the increase of PVB viscosity. Besides, shear modulus ratio has a greater influence than delay factor. The relaxation occurs in PVB interlayer during the impact, which leads to the decrease of PVB modulus. PVB modulus decreases faster with the increase 


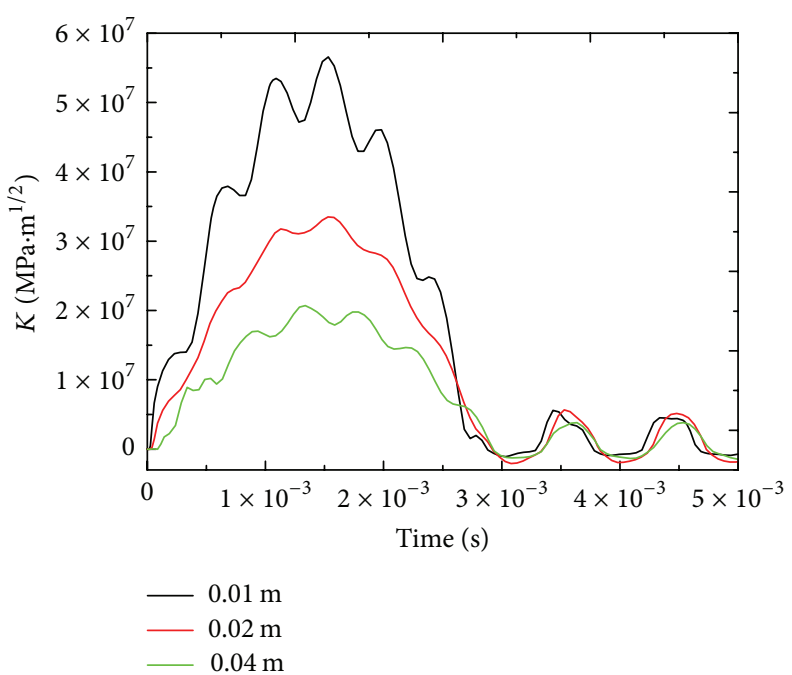

(a) Mode I DSIF curves of entire time course

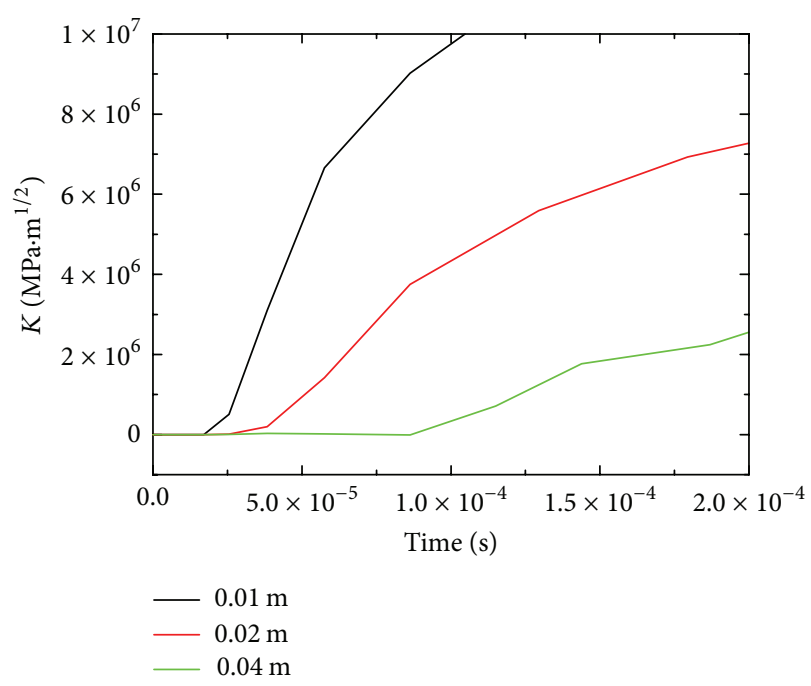

(b) Mode I DSIF curves before $2 \times 10^{-4} \mathrm{~s}$

FIGURE 11: Mode I DSIF curves at node 1 with different fixed crack lengths under the impact velocity of $5 \mathrm{~m} / \mathrm{s}$.

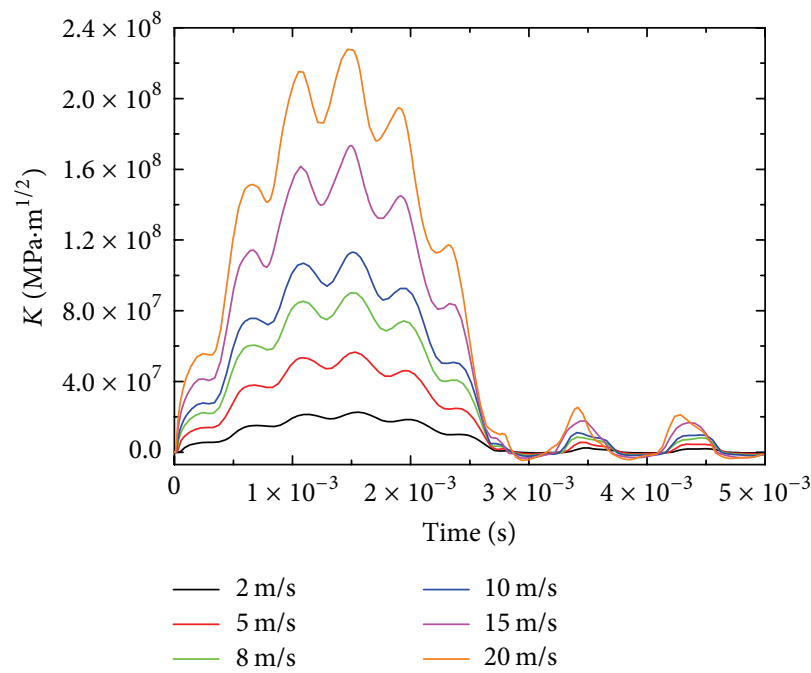

(a) Impact velocities

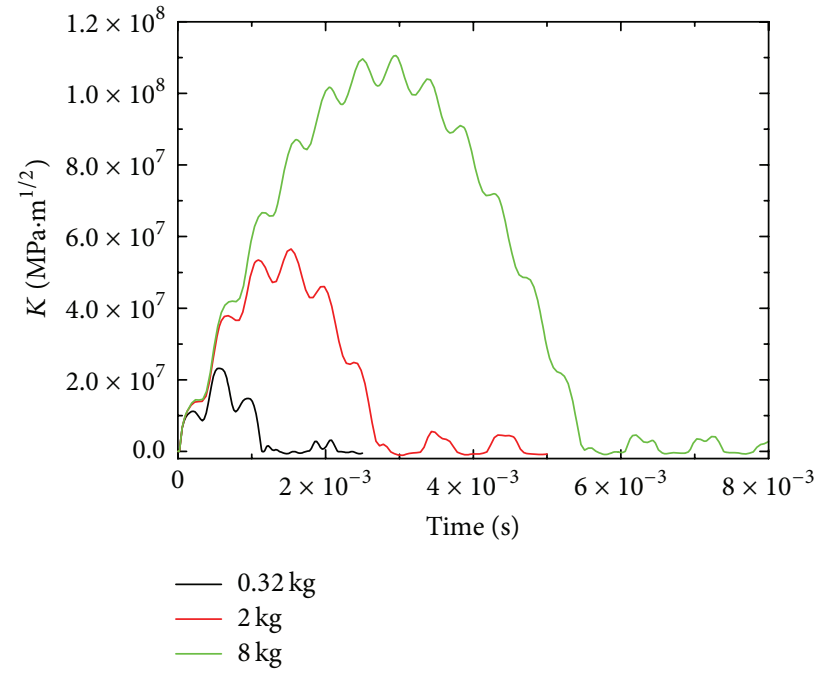

(b) Impact masses

FIGURE 12: Mode I DSIF curves at node 1 with crack length of $0.02 \mathrm{~m}$ under different impact energy.

of viscosity, which explains the viscosity effect. However, the stress wave propagation time is far less than the PVB relaxation time and only a small amount of relaxation occurs during the impact. Therefore, the influence of delay factor on DSIF is less obvious than shear modulus ratio.

\section{Concluding Remarks}

In this paper, the crack propagation characteristics of PVB laminated glass under low-speed impact are investigated in the framework of XFEM. A PVB laminated glass 3D model is proposed, which has been qualitatively and quantitatively validated via comparing with the experimental results captured by high-speed photography system. The verified numerical model with fixed crack is then used to systematically investigate the crack propagation behavior. The time history of brittle DSIFs as well as the propagations of stress waves is derived to interpret the crack propagation mechanism.

Further, five critical structure and material variables, that is, plate dimension, crack length, impact energy, glass properties, and PVB properties, are introduced to conduct parametric studies. It is found that the interaction between the crack tip and stress waves and the round-trip propagations of tension stress waves lead to the fluctuations of DSIFs, which corresponds to the influence of plate dimension and crack length. The impact energy and glass properties result in the changes of DSIF peak values and fluctuation frequencies, respectively. As longitudinal boundaries of cracks in glass 


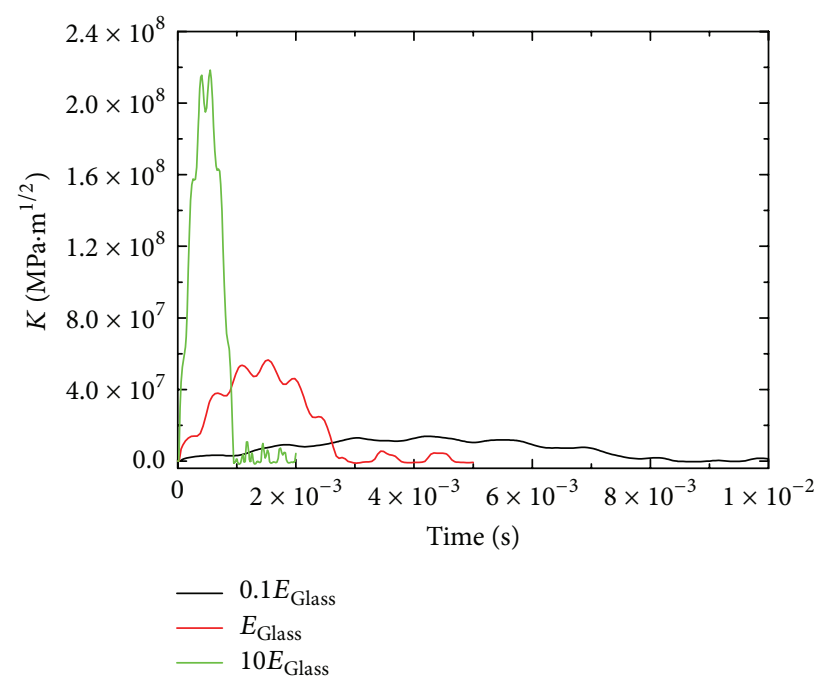

(a) Glass Young's modulus

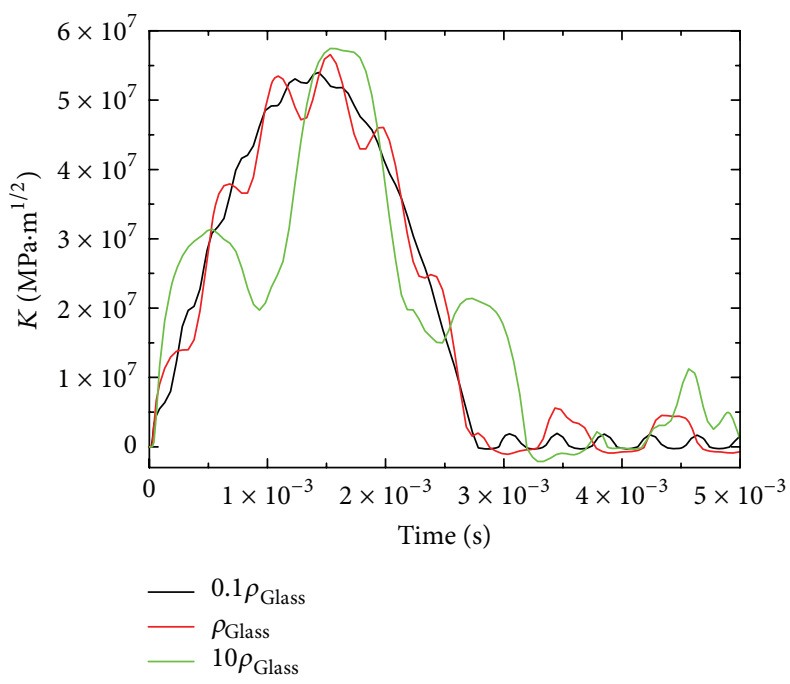

(b) Glass density

FIGURE 13: Mode I DSIF at node 1 of different glass properties with the impact velocity of $5 \mathrm{~m} / \mathrm{s}$ and crack length of $0.02 \mathrm{~m}$.
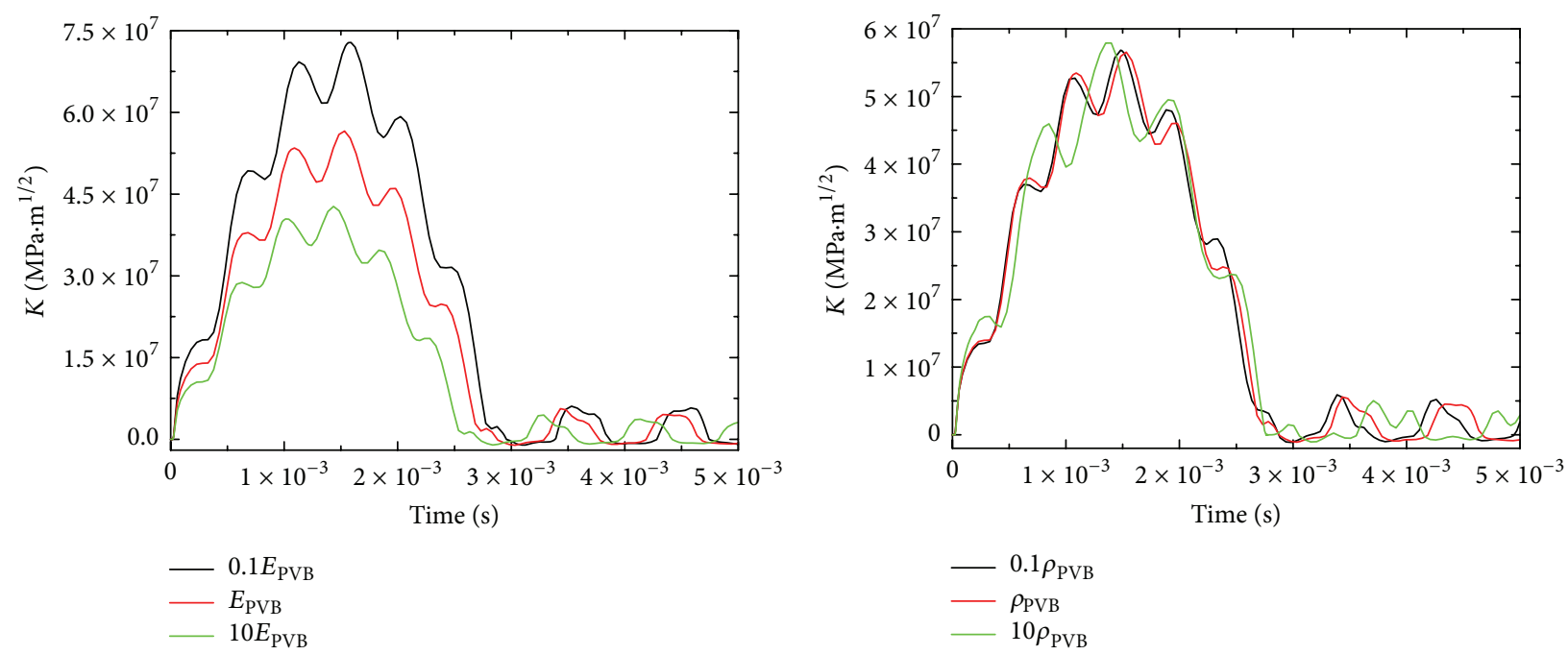

(a) PVB Young's modulus

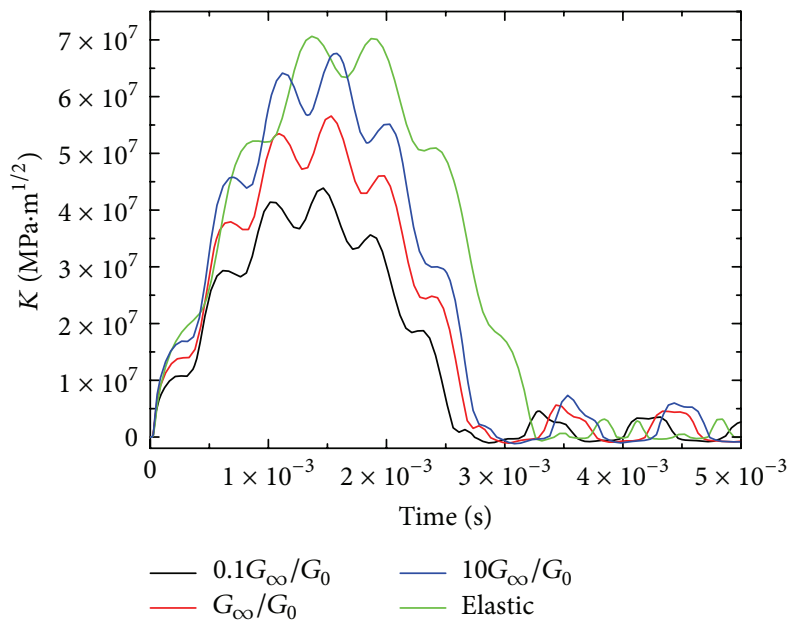

(c) Shear modulus ratio

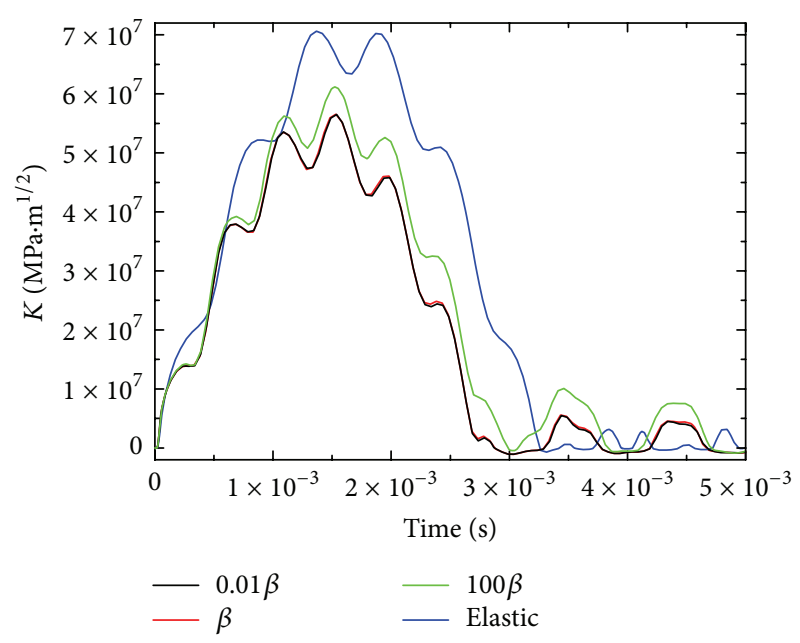

(d) Delay factor

FIGURE 14: Mode I DSIF at node 1 of different PVB properties with the impact velocity of $5 \mathrm{~m} / \mathrm{s}$ and crack length of $0.02 \mathrm{~m}$. 
layers, PVB interlayer has an important influence on DSIFs of glass layer.

This research may provide basic crack propagation laws for researches on cracking mechanism of PVB laminated glass under impact loading conditions in the future.

\section{Competing Interests}

The authors declare that they have no competing interests.

\section{Acknowledgments}

The work is supported by the National Natural Science Foundation of China (11372164 and 11102099) and Tsinghua University under Grants nos. 20121080050 and 20132001016.

\section{References}

[1] J. Belis, J. Depauw, D. Callewaert, D. Delincé, and R. Van Impe, "Failure mechanisms and residual capacity of annealed glass/SGP laminated beams at room temperature," Engineering Failure Analysis, vol. 16, no. 6, pp. 1866-1875, 2009.

[2] C. V. G. Vallabhan, Y. C. Das, M. Magdi, M. Asik, and J. R. Bailey, "Analysis of laminated glass units," Journal of Structural Engineering, vol. 119, no. 5, pp. 1572-1585, 1993.

[3] J. Xu, Y. Li, B. Liu, M. Zhu, and D. Ge, "Experimental study on mechanical behavior of PVB laminated glass under quasi-static and dynamic loadings," Composites Part B: Engineering, vol. 42, no. 2, pp. 302-308, 2011.

[4] G. Herndon, K. Allen, A. Roberts, D. Phillips, and S. A. Batzer, "Automotive side glazing failure due to simulated human interaction," Engineering Failure Analysis, vol. 14, no. 8, pp. 17011710, 2007.

[5] M. Larcher, G. Solomos, F. Casadei, and N. Gebbeken, "Experimental and numerical investigations of laminated glass subjected to blast loading," International Journal of Impact Engineering, vol. 39, no. 1, pp. 42-50, 2012.

[6] P. A. Hooper, R. A. M. Sukhram, B. R. K. Blackman, and J. P. Dear, "On the blast resistance of laminated glass," International Journal of Solids and Structures, vol. 49, no. 6, pp. 899-918, 2012.

[7] K. Fischer and I. Häring, "SDOF response model parameters from dynamic blast loading experiments," Engineering Structures, vol. 31, no. 8, pp. 1677-1686, 2009.

[8] X. Zhang, H. Hao, and G. Ma, "Laboratory test and numerical simulation of laminated glass window vulnerability to debris impact," International Journal of Impact Engineering, vol. 55, pp. 49-62, 2013.

[9] X. Zhang, H. Hao, and Z. Wang, "Experimental study of laminated glass window responses under impulsive and blast loading," International Journal of Impact Engineering, vol. 78, pp. 1-19, 2015.

[10] X. Zhang and H. Hao, "Experimental and numerical study of boundary and anchorage effect on laminated glass windows under blast loading," Engineering Structures, vol. 90, pp. 96-116, 2015.

[11] Y. Liu and B. Liaw, "Drop-weight impact tests and finite element modeling of cast acrylic/aluminum plates," Polymer Testing, vol. 28, no. 8, pp. 808-823, 2009.

[12] J. Stenzler and N. Goulbourne, "Impact mechanics of transparent multi-layered polymer composites," in Proceedings of the
Society for Experimental Mechanics-Sem Annual Conference and Exposition on Experimental and Applied Mechanics, 2009.

[13] H. Chai and G. Ravichandran, "On the mechanics of fracture in monoliths and multilayers from low-velocity impact by sharp or blunt-tip projectiles," International Journal of Impact Engineering, vol. 36, no. 3, pp. 375-385, 2009.

[14] H. Park and W. W. Chen, "Experimental investigation on dynamic crack propagating perpendicularly through interface in glass," Journal of Applied Mechanics, vol. 78, no. 5, Article ID 051013, 2011.

[15] A. J. Hsieh and J. W. Song, "Measurements of ballistic impact response of novel coextruded PC/PMMA multilayeredcomposites," Journal of Reinforced Plastics and Composites, vol. 20, no. 3, pp. 239-254, 2001.

[16] M. Hebert, C.-E. Rousseau, and A. Shukla, "Shock loading and drop weight impact response of glass reinforced polymer composites," Composite Structures, vol. 84, no. 3, pp. 199-208, 2008.

[17] J. J.-W. Lee, I. K. Lloyd, H. Chai, Y.-G. Jung, and B. R. Lawn, "Arrest, deflection, penetration and reinitiation of cracks in brittle layers across adhesive interlayers," Acta Materialia, vol. 55, no. 17, pp. 5859-5866, 2007.

[18] W. Zhang, S. Tekalur, and L. Huynh, "Impact behavior and dynamic failure of PMMA and PC plates," Dynamic Behavior of Materials, vol. 1, pp. 93-104, 2011.

[19] W. Hu, Y. Wang, J. Yu, C.-F. Yen, and F. Bobaru, "Impact damage on a thin glass plate with a thin polycarbonate backing," International Journal of Impact Engineering, vol. 62, pp. 152-165, 2013.

[20] N. Vandenberghe, R. Vermorel, and E. Villermaux, "Star-shaped crack pattern of broken windows," Physical Review Letters, vol. 110, no. 17, Article ID 174302, 2013.

[21] J. Xu, Y. Sun, B. Liu et al., "Experimental and macroscopic investigation of dynamic crack patterns in PVB laminated glass sheets subject to light-weight impact," Engineering Failure Analysis, vol. 18, no. 6, pp. 1605-1612, 2011.

[22] J. Chen, J. Xu, X. Yao et al., "Experimental investigation on the radial and circular crack propagation of PVB laminated glass subject to dynamic out-of-plane loading," Engineering Fracture Mechanics, vol. 112-113, pp. 26-40, 2013.

[23] J. Chen, J. Xu, X. Yao, X. Xu, B. Liu, and Y. Li, “Different driving mechanisms of in-plane cracking on two brittle layers of laminated glass," International Journal of Impact Engineering, vol. 69, pp. 80-85, 2014.

[24] J. Chen, J. Xu, B. Liu, X. Yao, and Y. Li, "Quantity effect of radial cracks on the cracking propagation behavior and the crack morphology," PLoS ONE, vol. 9, no. 7, Article ID e98196, 2014.

[25] M. Timmel, S. Kolling, P. Osterrieder, and P. A. Du Bois, "A finite element model for impact simulation with laminated glass," International Journal of Impact Engineering, vol. 34, no. 8, pp. 1465-1478, 2007.

[26] H. Hao and X. Zhang, "Analysis and design of glass windows against blast and impact loads," in Proceedings of the 11th International Conference on Shock \& Impact Loads on Structures, Ottawa, Canada, 2015.

[27] T. Pyttel, H. Liebertz, and J. Cai, "Failure criterion for laminated glass under impact loading and its application in finite element simulation," International Journal of Impact Engineering, vol. 38, no. 4, pp. 252-263, 2011. 
[28] Y. Peng, J. Yang, C. Deck, and R. Willinger, "Finite element modeling of crash test behavior for windshield laminated glass," International Journal of Impact Engineering, vol. 57, pp. 27-35, 2013.

[29] F. W. Flocker and L. R. Dharani, "Modelling fracture in laminated architectural glass subject to low velocity impact," Journal of Materials Science, vol. 32, no. 10, pp. 2587-2594, 1997.

[30] D. Sun, F. Andreiux, and A. Ockewitz, "Modeling of the failure behavior of windscreens and component tests," in Proceedings of the 4th LS-DYNA Users Conference, Bamberg, Germany, 2005.

[31] X. Zhang, H. Hao, and G. Ma, "Parametric study of laminated glass window response to blast loads," Engineering Structures, vol. 56, pp. 1707-1717, 2013.

[32] M. Larcher, M. Teich, N. Gebbeken et al., "Simulation of laminated glass loaded by air blast waves," Applied Mechanics and Materials, vol. 82, pp. 69-74, 2011.

[33] S. J. Bennison, A. Jagota, and C. A. Smith, "Fracture of glass/poly(vinyl butyral) (Butacite ${ }^{\circledR}$ ) laminates in biaxial flexure," Journal of the American Ceramic Society, vol. 82, no. 7, pp. 1761-1770, 1999.

[34] J. Xu and Y. Li, "Crack analysis in PVB laminated windshield impacted by pedestrian head in traffic accident," International Journal of Crashworthiness, vol. 14, no. 1, pp. 63-71, 2009.

[35] W. Xu and M. Zang, "Four-point combined DE/FE algorithm for brittle fracture analysis of laminated glass," International Journal of Solids and Structures, vol. 51, no. 10, pp. 1890-1900, 2014.

[36] M. Y. Zang, Z. Lei, and S. F. Wang, "Investigation of impact fracture behavior of automobile laminated glass by $3 \mathrm{D}$ discrete element method," Computational Mechanics, vol. 41, no. 1, pp. 73-83, 2007.

[37] W. Gao and M. Zang, "The simulation of laminated glass beam impact problem by developing fracture model of spherical DEM," Engineering Analysis with Boundary Elements, vol. 42, pp. 2-7, 2014.

[38] S. Chen, M. Zang, D. Wang, Z. Zheng, and C. Zhao, "Finite element modelling of impact damage in polyvinyl butyral laminated glass," Composite Structures, vol. 138, pp. 1-11, 2016.

[39] X. Xu, J. Chen, J. Xu, Y. Li, and X. Yao, "Modeling and experimental studies of crack propagation in laminated glass sheets," SAE International Journal of Materials \& Manufacturing, vol. 7, no. 2, pp. 328-336, 2014.

[40] J. Xu, Y. Li, X. Chen et al., "Characteristics of windshield cracking upon low-speed impact: numerical simulation based on the extended finite element method," Computational Materials Science, vol. 48, no. 3, pp. 582-588, 2010.

[41] J. Xu, Y. Li, X. Chen et al., "Numerical study of PVB laminated windshield cracking upon human head impact," Computers, Materials \& Continua, vol. 18, no. 2, pp. 183-211, 2010.

[42] S. Zhao, L. R. Dharani, L. Chai, and S. D. Barbat, "Analysis of damage in laminated automotive glazing subjected to simulated head impact," Engineering Failure Analysis, vol. 13, no. 4, pp. 582-597, 2006.

[43] J. Dolbow and T. Belytschko, "A finite element method for crack growth without remeshing," International Journal for Numerical Methods in Engineering, vol. 46, pp. 131-150, 1999.

[44] T. Belytschko and T. Black, "Elastic crack growth in finite elements with minimal remeshing," International Journal for Numerical Methods in Engineering, vol. 45, no. 5, pp. 601-620, 1999.
[45] T. Belytschko, N. Moës, S. Usui, and C. Parimi, "Arbitrary discontinuities in finite elements," International Journal for Numerical Methods in Engineering, vol. 50, no. 4, pp. 993-1013, 2001.

[46] ABAQUS 6.13 analysis user's guide, Dassault Systems, 2013.

[47] J. Lambros and A. J. Rosakis, "Dynamic crack initiation and growth in thick unidirectional graphite/epoxy plates," Composites Science and Technology, vol. 57, no. 1, pp. 55-65, 1997.

[48] X. Zhang, Y. Zou, H. Hao, X. Li, G. Ma, and K. Liu, "Laboratory test on dynamic material properties of annealed float glass," International Journal of Protective Structures, vol. 3, no. 4, pp. 407-430, 2012.

[49] M. Peroni, G. Solomos, V. Pizzinato, and M. Larcher, "Experimental investigation of high strain-rate behaviour of glass," Applied Mechanics and Materials, vol. 82, pp. 63-68, 2011.

[50] L. Freund, Dynamic Fracture Mechanics, Cambridge University Press, Cambridge, UK, 1998. 

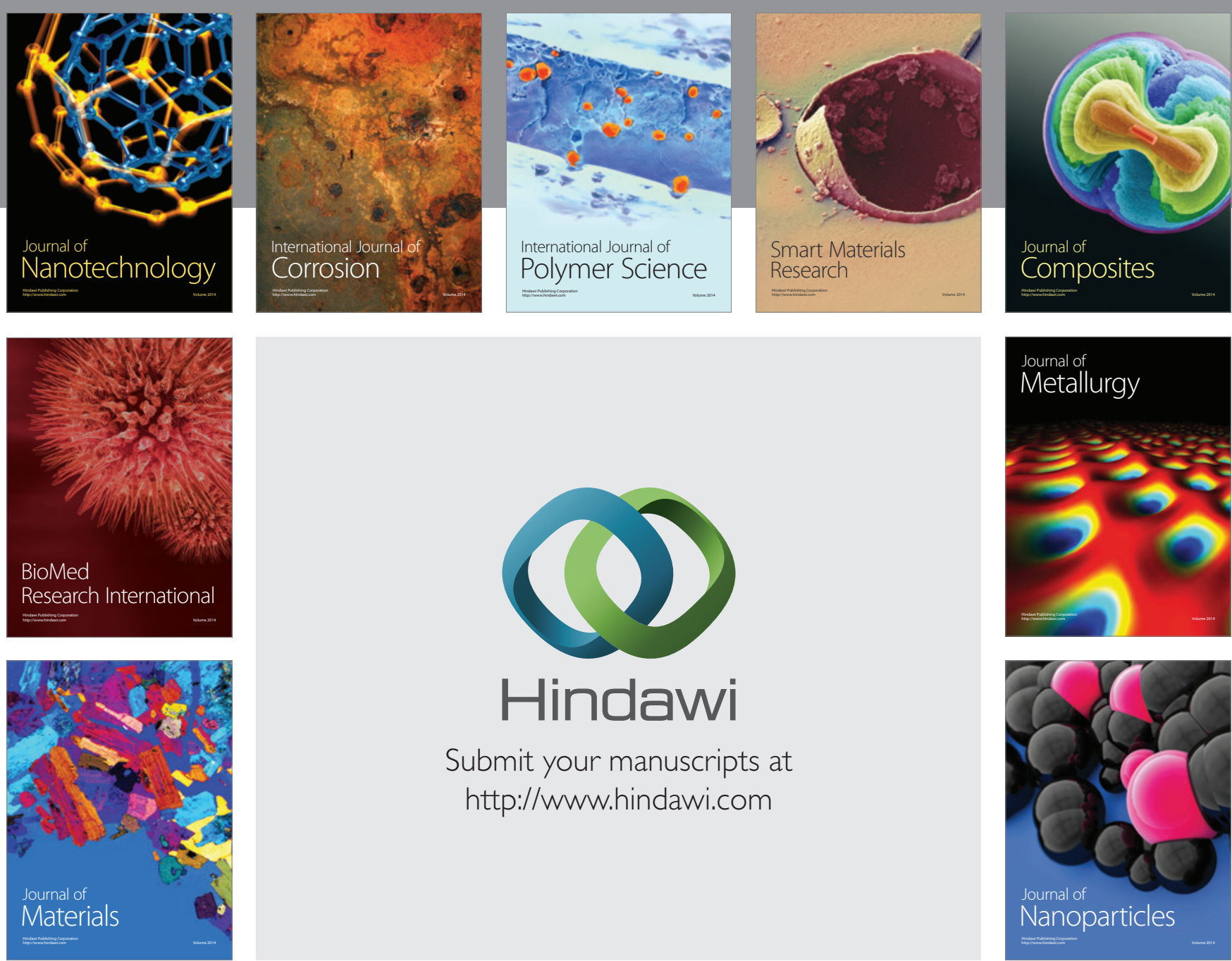

\section{Hindawi}

Submit your manuscripts at

http://www.hindawi.com

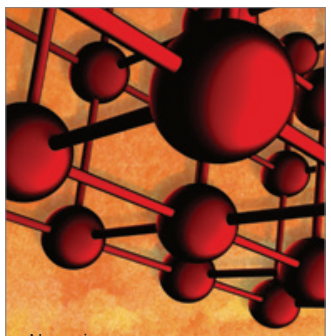

Materials Science and Engineering
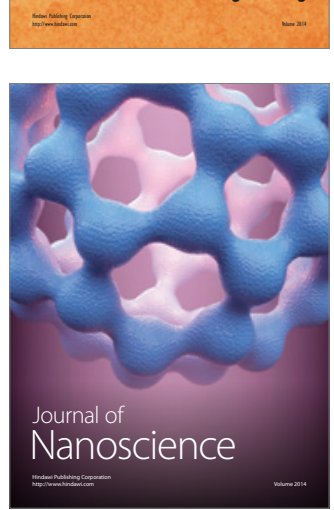
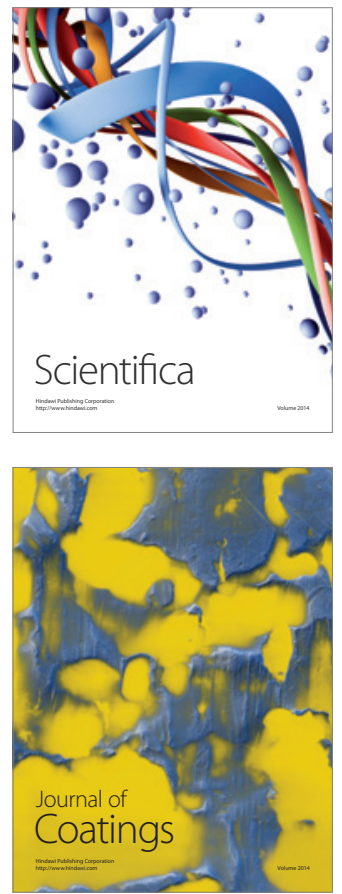
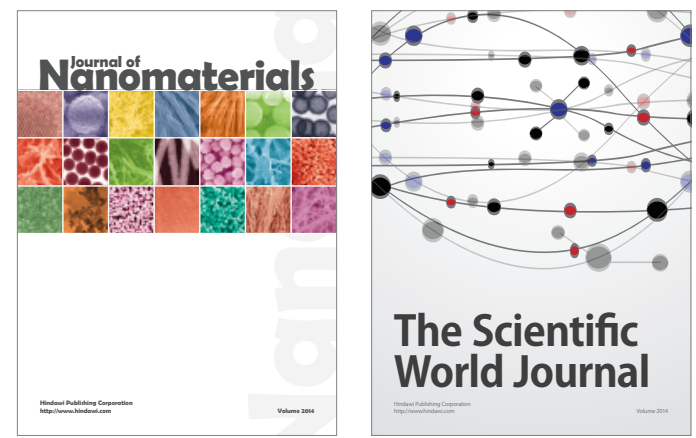

The Scientific World Journal
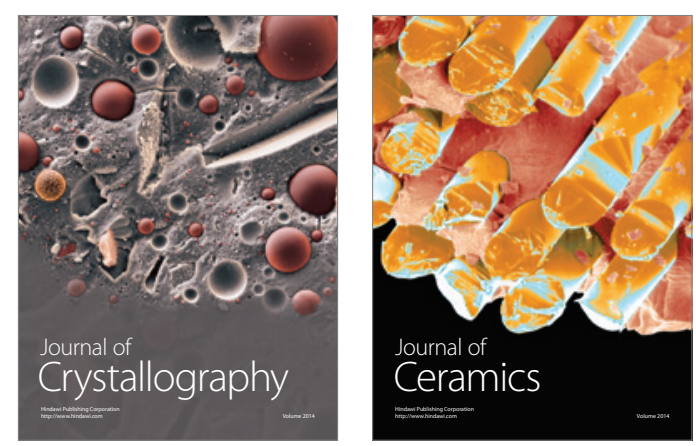
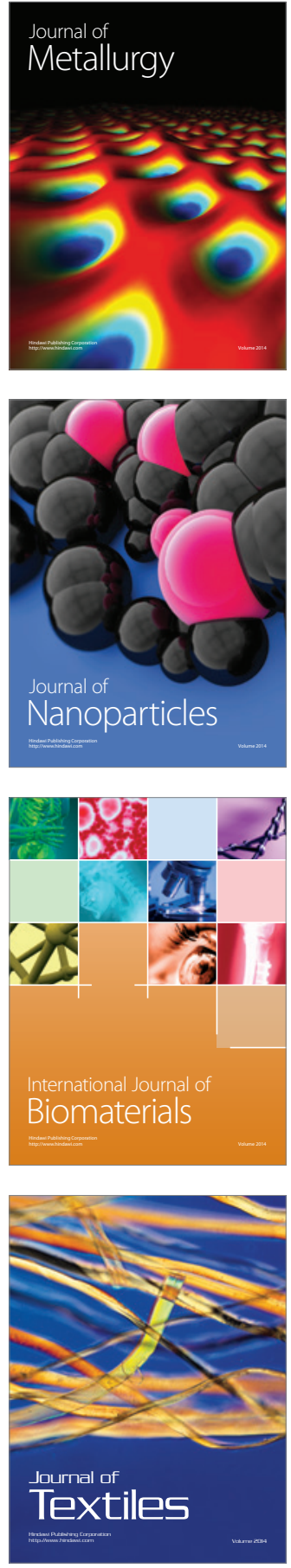